OPEN ACCESS

Edited by:

Chew Chieng Yeo,

Universiti Sultan Zainal Abidin,

Malaysia

Reviewed by:

Manuel Espinosa,

Centro de Investigaciones Biológicas

(CSIC), Spain

Darío García De Viedma,

Hospital General Universitario

Gregorio Marañón, Spain

Analia Rial,

Facultad de Medicina, Universidad de

la Republica de Uruguay, Uruguay

Natalia Munoz Wolf,

Trinity College, Dublin, Ireland

*Correspondence:

Ernesto García

e.garcia@cib.csic.es

Specialty section:

This article was submitted to

Evolutionary and Genomic

Microbiology,

a section of the journal

Frontiers in Microbiology

Received: 27 January 2017 Accepted: 30 June 2017

Published: 18 July 2017

Citation:

Domenech M and García E (2017)

Fluorescence Imaging of

Streptococcus pneumoniae with the

Helix pomatia agglutinin (HPA) As a

Potential, Rapid Diagnostic Tool.

Front. Microbiol. 8:1333.

doi: 10.3389/fmicb.2017.01333

\section{Fluorescence Imaging of Streptococcus pneumoniae with the Helix pomatia agglutinin (HPA) As a Potential, Rapid Diagnostic Tool}

\author{
Mirian Domenech ${ }^{1,2}$ and Ernesto García ${ }^{1,2 *}$ \\ ${ }^{1}$ Departamento de Microbiología Molecular y Biología de las Infecciones, Centro de Investigaciones Biológicas, Consejo \\ Superior de Investigaciones Científicas, Madrid, Spain, ${ }^{2}$ Centro de Investigación Biomédica en Red de Enfermedades \\ Respiratorias, Madrid, Spain
}

Streptococcus pneumoniae is a common human pathogen and a major causal agent of life-threatening infections that can either be respiratory or non-respiratory. It is well known that the Helix pomatia (edible snail) agglutinin (HPA) lectin shows specificity for terminal $\alpha$ GalNAc residues present, among other locations, in the Forssman pentasaccharide $(\alpha$ GalNAc1 $\rightarrow 3 \beta$ GalNAc1 $\rightarrow 3 \alpha$ Gal $1 \rightarrow 4 \beta$ Gal $1 \rightarrow 4 \beta$ Glc). Based on experiments involving choline-independent mutants and different growth conditions, we propose here that HPA recognizes the $\alpha$ GalNAc terminal residues of the cell wall teichoic and lipoteichoic acids of $S$. pneumoniae. In addition, experimental evidence showing that pneumococci can be specifically labeled with HPA when growing as planktonic cultures as well as in mixed biofilms of $S$. pneumoniae and Haemophilus influenzae has been obtained. It should be underlined that pneumococci were HPA-labeled despite of the presence of a capsule. Although some non-pneumococcal species also bind the agglutinin, HPA-binding combined with fluorescence microscopy constitutes a suitable tool for identifying S. pneumoniae and, if used in conjunction with Gram staining and/or other suitable technique like antigen detection, it may potentially facilitate a fast and accurate diagnosis of pneumococcal infections.

Keywords: Streptococcus pneumoniae, Forssman antigen, binding lectins, teichoic acids, fluorescence microscopy

\section{INTRODUCTION}

Streptococcus pneumoniae, the pneumococcus, is a leading human pathogen and one of the foremost etiologic agents of invasive diseases such as bacteremic community-acquired pneumonia (CAP), bacteremia, and meningitis, mainly in children, the elderly, and immunocompromised patients. Indeed, the pneumococcus is one of the major causes of non-invasive diseases such as non-bacteremic CAP, acute otitis media, sinusitis and conjunctivitis. In 2015, CAP accounted for $16 \%$ of all deaths of children under 5 years old globally and 920,000 deaths globally in children of all ages (World Health Organization, 2016). S. pneumoniae is the commonest bacterial causative agent across all ages, accounting for 30-40\% of CAP cases (Haq et al., 2017). Other bacterial causes of CAP include Streptococcus pyogenes (group A streptococci; GAS), and Streptococcus agalactiae (group B streptococci; GBS) in infants. Staphylococcus aureus is associated with round pneumonia, a welldefined round area of consolidation visible on chest radiographs. Despite the current vaccination 
programs, Haemophilus influenzae remains prevalent in several developing countries (Hajjeh et al., 2013) and Mycoplasma pneumoniae accounts for up to a third of all cases and is a common cause of atypical CAP.

Since mortality rates are highest during the first days of admission (Ewig et al., 2009), early diagnosis and treatment may have a crucial role in curing the patient or in reducing their morbidity and mortality, particularly in the era of antibiotic resistance (Vila et al., 2017). Rapid identification techniques are even more important in bacterial meningitis patients, since delayed initiation of antibiotic treatment is strongly associated with death and poor outcome; as a consequence, it has been recently recommended that antibiotic treatment in these patients should be started as soon as possible, and the time period from entering the hospital to initiation of antibiotic treatment should not exceed $1 \mathrm{~h}$ (van de Beek et al., 2016). In every case, the gold standard diagnostic method is still culture. Unfortunately, this is time consuming (24-72 h) and includes the inoculation of appropriate media, subculturing, and phenotype-based characterization via biochemical testing, along with antibiotic susceptibility testing. Currently, bacteriological diagnosis is making progress in molecular biology techniques such as PCR, matrix-assisted laser desorption/ionization timeof-flight mass spectrometry (MALDI-TOF MS), and whole genome sequencing (Clark, 2015; Pai et al., 2015; McGill et al., 2016; Torres et al., 2016). These techniques have been developed to decrease the time for the initiation of an optimal antimicrobial therapy for improving clinical outcomes. Unfortunately, although microbiological diagnosis is very important for a correct clinical management of the diseaseparticularly because spreading of antibiotic multiresistance is an increasing global concern-, microbiological identification is lacking in many instances approaching 50\% in CAP cases (Cilloniz et al., 2016).

Most bacteria in nature exist in multispecies communities known as biofilms. Multispecies biofilms are structured and spatially defined communities where species interact both intraand interspecifically (Røder et al., 2016). Imaging techniques are useful for identifying multiple species, which provides information on their spatial organization. Fluorescence in situ hybridization (FISH) and many advanced versions of the FISH technique have been implemented for different purposes; these are well-established means of visualizing and identifying microbial groups or species in natural and artificially created multispecies biofilms (Amann and Fuchs, 2008; Liu et al., 2016; Røder et al., 2016). Although FISH is typically timeconsuming and destructive to the samples, it is however possible to visualize different species simultaneously (Schimak et al., 2016). Fluorescence imaging of individual species can also be achieved by genetically marking the species with genes coding for different fluorescent or bioluminescent proteins (Kjos et al., 2015). Unfortunately, not all bacteria can be fluorescently tagged, particularly those from natural samples.

Polymicrobial biofilms are abundant in clinical diseases such as acute otitis media, a significant public health problem worldwide (Monasta et al., 2012), particularly among children (Ahmed et al., 2014). Acute otitis media is preceded by the nasopharyngeal carriage of bacterial pathogens like $S$. pneumoniae, non-typeable (NT) H. influenzae, and Moraxella catarrhalis (Ngo et al., 2016). Moreover, the concurrent carriage of these pathogens is a predictor of clinical pneumonia (Chochua et al., 2016). When growing in an in vitro mixed biofilm, S. pneumoniae and NT $H$. influenzae cells appear to accomplish a strong inter-population cooperation, i.e., metabolic interdependence or mutualism (Momeni et al., 2013), as indicated by the finding that pneumococci were intermixed with NT $H$. influenzae cells throughout the biofilm (Domenech and García, 2017). This was determined using the Helix pomatia (edible snail) agglutinin (HPA) that unambiguously stained $S$. pneumoniae cells in the mixed biofilms. The binding preference of HPA has been reported to be the Forssman pentasaccharide $(\alpha \mathrm{GalNAc} 1 \rightarrow 3 \beta \mathrm{GalNAc} 1 \rightarrow 3 \alpha \mathrm{Gal} 1 \rightarrow 4 \beta \mathrm{Gal} 1 \rightarrow 4 \beta \mathrm{Glc})$

$>$ blood group A substance $(\alpha \mathrm{GalNAc1} \rightarrow 3[\alpha \mathrm{Fuc} 1 \rightarrow 2] \mathrm{Gal}]$ $>$ Tn antigen ( $\alpha$ GalNAc-Ser/Thr $)>$ GalNAc > GlcNAc, confirming its specificity for terminal $\alpha$ GalNAc residues (Wu and Sugii, 1991; Cooling, 2015). The Forssman antigen (FA) can be defined as a substance that provokes the appearance of sheep red blood cell hemolytic antibodies when injected into rabbits; it is a glycolipid with the structure GalNAc $\alpha 1 \rightarrow 3$ GalNAc $\beta 1 \rightarrow 3 \mathrm{Gal} \alpha 1 \rightarrow 4 \mathrm{Gal} \beta 1 \rightarrow 4 \mathrm{Glc} \beta 1 \rightarrow 1 \mathrm{Cer}$

(Siddiqui and Hakomori, 1971). Originally found in the tissues of different animals (although not humans; Yamamoto et al., 2012), FA was subsequently discovered in some bacteria, including S. pneumoniae (Jenkin, 1963). It has been shown that the Forssman cross-reactive material of $S$. pneumoniae is the type IV, ribitol phosphate-containing, membrane anchored lipoteichoic acid (pnLTA) (Briles and Tomasz, 1973; Gisch et al., 2013). The non-lipid terminus of pnLTA consists of 6-O-PCho- $\alpha$-D-Gal $p$ NAc- $(1 \rightarrow 3)-6-O-P C h o-\beta-D-G a l p N A c$ (Seo et al., 2008); this disaccharide represents a structural feature that is able to partly explain the FA properties of pnLTA (Gisch et al., 2013). In addition and unlike other bacterial species, pnLTA and the $S$. pneumoniae peptidoglycan-bound teichoic acid (pnWTA) have identical chain structures (for a recent review, see reference by Gisch et al. (2015a). Based on this information it can be assumed that HPA binds to both WTA and LTA of S. pneumoniae.

In the present study we report that HPA binds to the teichoic acids (TA) of encapsulated and non-encapsulated pneumococcal cells grown either planktonically or forming biofilms. In addition to $S$. pneumoniae, HPA labeling of other bacterial species, e.g., some $S$. aureus strains, has also been observed. We propose that, in combination with other widespread rapid techniques, labeling with HPA in biological fluids may represent a helpful technique for the fast and accurate diagnosis of pneumococcal diseases.

\section{MATERIALS AND METHODS Bacteria and Growth Conditions}

The bacteria used in this study are listed in Table 1. Streptococci, staphylococci, enterococci, and Pseudomonas aeruginosa were grown in Todd-Hewitt broth supplemented with $0.5 \%$ yeast extract (THY). For planktonic growth, the NT H. influenzae strain 54997 was incubated in brain heart infusion (BHI) 
TABLE 1 | Bacterial strains used in this study.

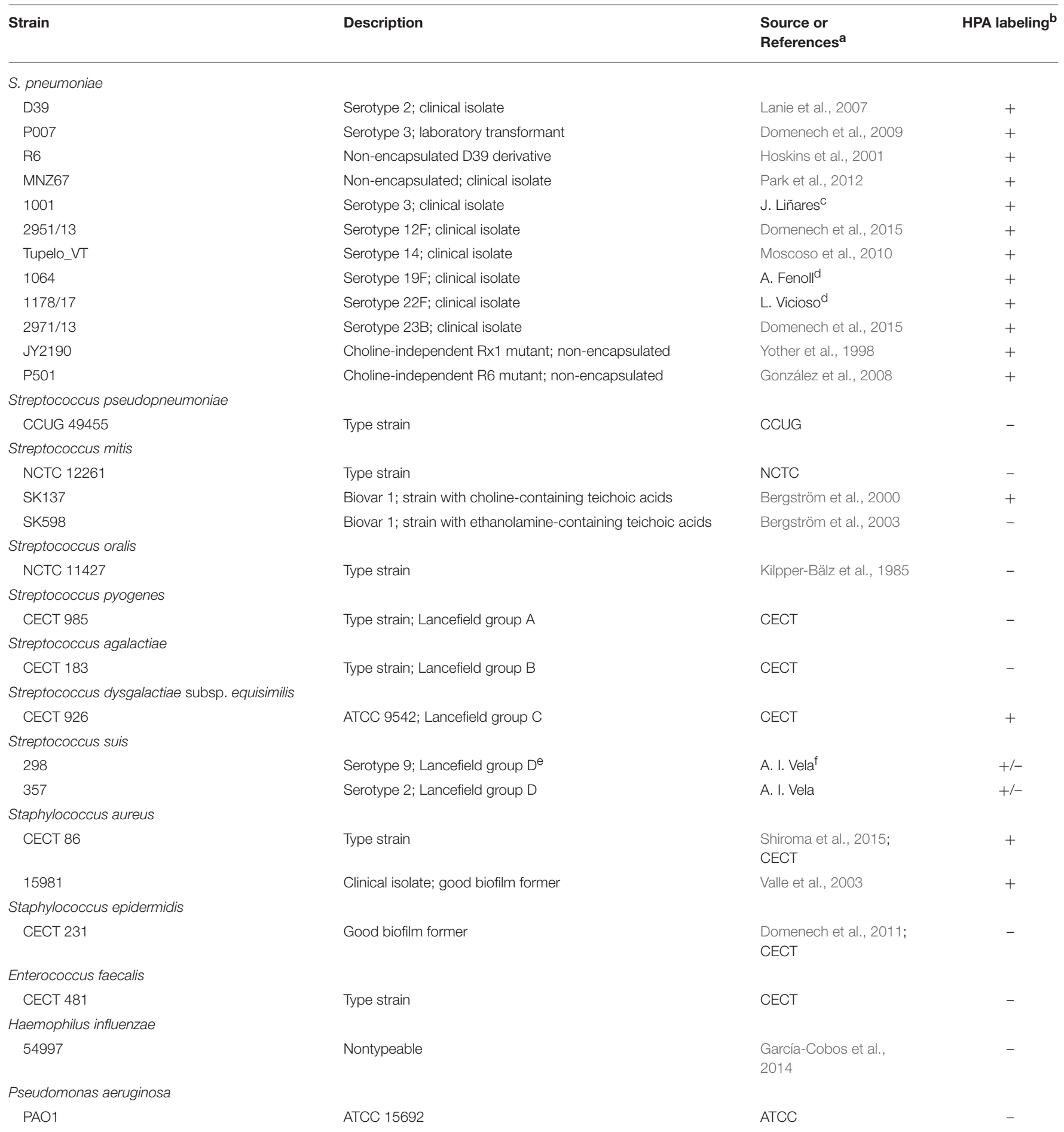

${ }^{a}$ ATCC, American Type Culture Collection; CECT, Colección Española de Cultivos Tipo; CCUG, Culture Collection, University of Göteborg; NCTC, National Collection of Type Cultures. ${ }^{b}+$, positive; -, negative; +/-, slightly positive.

cInstituto de Investigación Biomédica de Bellvitge (IDIBEL); Barcelona (Spain).

${ }^{d}$ Laboratorio de Referencia de Neumococos; Centro Nacional de Microbiología (CNM-ISCIII); Majadahonda (Madrid; Spain).

${ }^{e}$ Although early studies reported that some strains of S. suis contained streptococcal group D antigen, more recent results indicated that the group $R$ and group $D$ antigens were similar and crossreacted. To date, the species belonging to the Streptococcus bovis group constitute the non-enterococcal group D streptococci (Dekker and Lau, 2016).

${ }^{f}$ Facultad de Veterinaria; Universidad Complutense de Madrid; Madrid (Spain). 
supplemented with haemin and NAD (15 $\mu \mathrm{g} / \mathrm{ml}$ each) (sBHI). In some experiments, $S$. pneumoniae was grown in $\mathrm{C}$ medium (Lacks and Hotchkiss, 1960) supplemented with $0.08 \%$ yeast extract (Difco Laboratories; $\mathrm{C}+\mathrm{Y}$ medium) or a chemically defined medium (Cden) supplemented (or not) with either choline $(5 \mu \mathrm{g} / \mathrm{ml})$ (Cden-choline) or ethanolamine $(40 \mu \mathrm{g} / \mathrm{ml})$ (Cden-EA) (Tomasz, 1968). Cells were incubated at $37^{\circ} \mathrm{C}$ without shaking. Bacterial growth was monitored by measuring the absorbance at $595 \mathrm{~nm}\left(A_{595}\right)$.

Formation of mixed biofilms of $S$. pneumoniae and NT $H$. influenzae was performed as described elsewhere (Domenech and García, 2017). Briefly, cultures of S. pneumoniae strain R6 and $H$. influenzae strain 54997 were grown to mid-exponential phase in $\mathrm{C}+\mathrm{Y}$ medium supplemented with haemin and NAD $(15 \mu \mathrm{g} / \mathrm{ml}$ each $)[\mathrm{s}(\mathrm{C}+\mathrm{Y})]$, diluted to $\approx 5 \times 10^{6}$ colony-forming units $(\mathrm{cfu}) / \mathrm{ml}$ and mixed in an 1:1 proportion. Two milliliter of the mixtures were then distributed into the wells of a glass-bottomed dish (WillCo-dish, WillCo Wells B. V., The Netherlands) and incubated for $6 \mathrm{~h}$ at $37^{\circ} \mathrm{C}$ under $5 \% \mathrm{CO}_{2}$. For species biofilm formation, $2 \mathrm{ml}$ of the individual cultures $\left(5 \times 10^{6}\right.$ $\mathrm{cfu} / \mathrm{ml}$ each) were independently inoculated as indicated above for mixed biofilms.

All studies which involved the handling of virulent bacteria, whole blood, or blood derivatives were undertaken at the biosafety level II laboratory of Centro de Investigaciones Biológicas. It should be mentioned that, according to the supplier (Innovative Research), the whole human blood used had been tested by FDA-approved methods for human immunodeficiency virus RNA, antibodies to immunodeficiency virus, antibodies to hepatitis $C$ virus, hepatitis $C$ virus $R N A$, hepatitis $B$ virus, hepatitis B surface antigen, and syphilis.

\section{Staining with HPA Lectin}

Exponentially growing cells of various bacterial species were centrifuged, washed and suspended in phosphate-buffered saline (PBS). After incubation for $15 \mathrm{~min}$ at room temperature in the dark with HPA lectin conjugated to Alexa Fluor-488 (2.5$25 \mu \mathrm{g} / \mathrm{ml}$ ), cells were centrifuged again and resuspended in PBS. Bacteria were observed under a Leica DM4000B fluorescence microscope equipped with an L5 filter (bandpass 480/40), and viewed under a Leica HCX PL FLUOTAR $40 \times / 0.75$ objective or an HC PL APO $63 \times / 1.40-0.60$ oil objective. In early experiments, bacteria were also diluted into fetal bovine serum (from SigmaAldrich), or into defibrinated sheep blood (from Biomedics or Oxoid). Afterwards, experiments were also carried out with groups $\mathrm{A}$ and $\mathrm{O}$ citrated human whole blood (from Innovative Research). It should be underlined that since HPA labeling does not require the presence of divalent cations (Kobayashi et al., 2014), blood treated to prevent its coagulation (e.g., citrate- or EDTA-treated) can be used.

For biofilm observation, the culture medium was removed and the biofilm rinsed with sterile water to remove non-adherent bacteria. Staining was performed with HPA and SYTO 59 and biofilms were gently rinsed with PBS. Observations were made using a Leica TCS-SP2-AOBS-UV confocal laser scanning microscope (CLSM) equipped with an argon ion laser. Images were analyzed using LCS software from Leica. Projections were obtained in the planes $x-y$ (individual scans at $0.5 \mu \mathrm{m}$ intervals) and $x-z$ (images at $5 \mu \mathrm{m}$ intervals).

\section{RESULTS}

\section{HPA Binding by Different Bacteria}

Pneumococci were clearly labeled with HPA when this was present in concentrations of $2.5-25 \mu \mathrm{g} / \mathrm{ml}$ (Figure 1). Closer examination showed that HPA labeling was not uniform across the pneumococcal surface; reduced fluorescence was noticed in the equatorial zone of growth, the place where new cell wall material is incorporated (Gisch et al., 2015a). The ability to bind HPA was not exclusive to pneumococci; the surfaces of other bacteria too were labeled with the lectin, i.e., Streptococcus mitis SK137 and some strains of Streptococcus dysgalactiae subsp. equisimilis, Streptococcus suis and S. aureus (Figure 2, Table 1). Notably, HPA was unable to label the type strains $\left({ }^{\mathrm{T}}\right)$ of Streptococcus pseudopneumoniae, S. mitis, or Streptococcus oralis, the three closest relatives of the pneumococcus. Notably, cells of other relevant pathogens, either Gram-positive (GAS, GBS, Enterococcus faecalis and Staphylococcus epidermidis) or Gram-negative ( $H$. influenzae and $P$. aeruginosa), did not bind the lectin (Table 1 ). Besides, and in agreement with previous results (Domenech and García, 2017), S. pneumoniae (but not NT H. influenzae) were also labeled with HPA when growing as mixed biofilms (Figure 3).

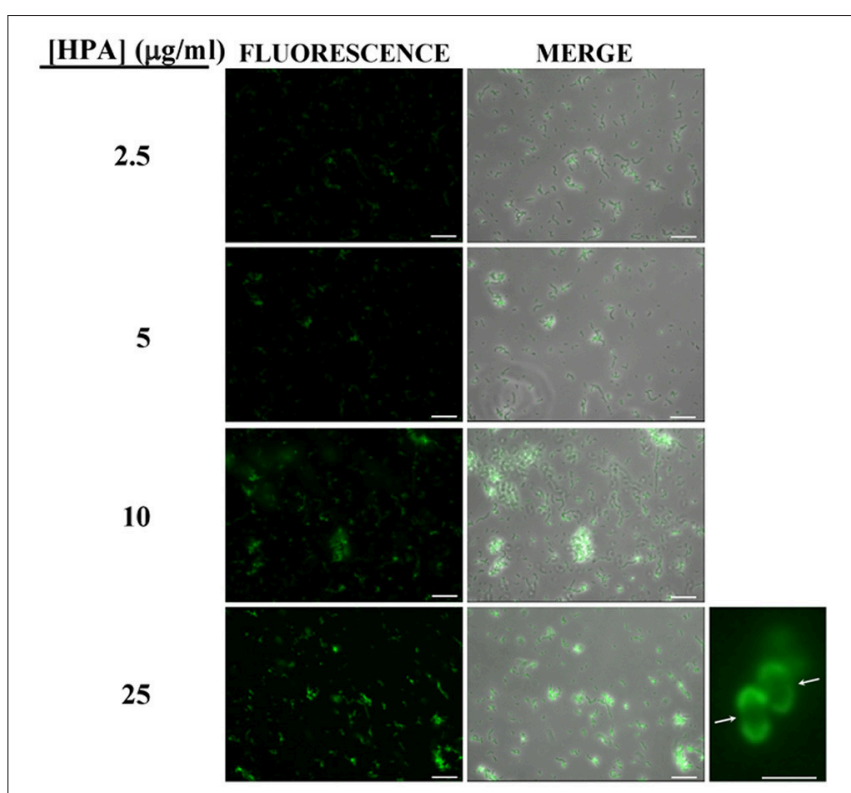

FIGURE 1 | Fluorescent labeling of the non-encapsulated S. pneumoniae strain R6 with HPA. Exponentially growing cultures of $S$. pneumoniae R6 in $\mathrm{C}+\mathrm{Y}$ medium were incubated with the indicated concentrations of the lectin and observed for fluorescence (HCX PL FLUOTAR 40×/0.75 objective). Merges of fluorescence and phase-contrast images are also shown; bar = $25 \mu \mathrm{m}$. Enlarged view of two diplococci showing reduced fluorescence at the equatorial zone of growth (indicated by arrows; $63 \times$ objective). Bar $=2 \mu \mathrm{m}$. 
A
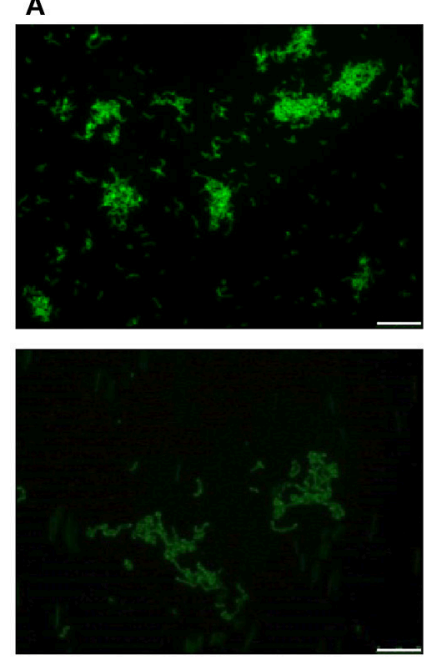

D
B
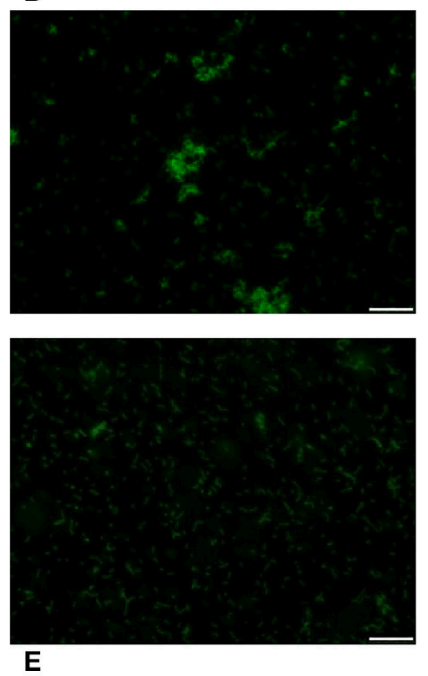

C
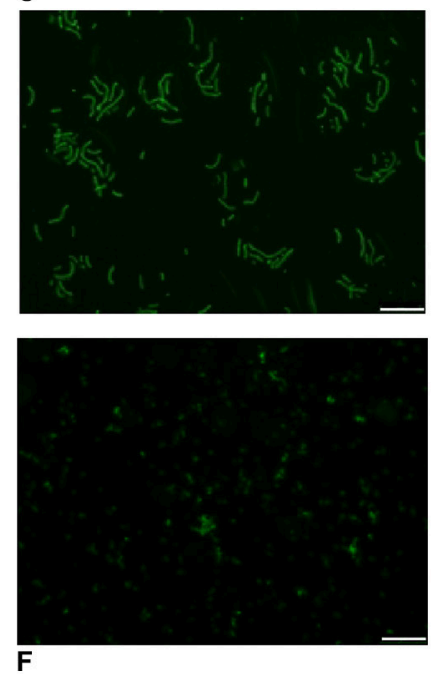

FIGURE 2 | HPA labeling of various streptococci in C+Y medium. First row: S. pneumoniae strains R6 (non-encapsulated) (A), D39 (serotype 2) (B), and P007 (serotype 3) (C). Second row: S. suis 298 (D), S. dysgalactiae subsp. equisimilis CECT 926 (E), and S. aureus type strain (F). Bar $=25 \mu \mathrm{m}$.
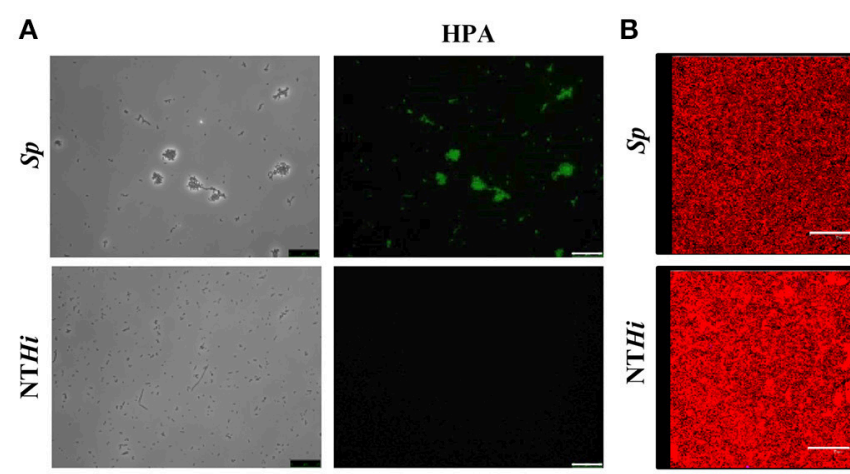

C
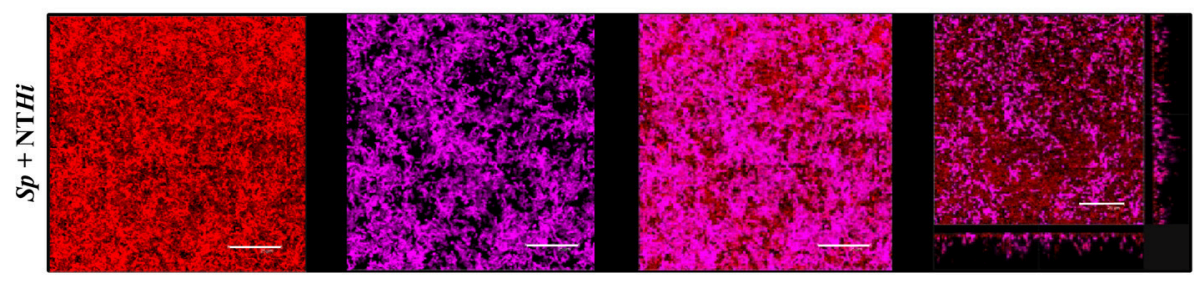

FIGURE 3 | S. pneumoniae labeling with HPA in mixed biofilms. (A) Fluorescent labeling of the S. pneumoniae (Sp) strain R6 and the non-typeable H. influenzae (NTHi) 54997 with HPA. Biofilms formed by Sp R6 or NTHi 54997 (B), or both pathogens (C) were stained with a combination of SYTO 59 (red) and HPA conjugated to Alexa Fluor-488 (pink). An orthogonal projection of a CLSM image showing a representative region of the $x-y$ plane over the depth of the biofilm in both $x-z$ and $y-z$ dimensions of the mixed biofilm is also shown at the bottom right part of the figure. Planktonic and biofilms cultures were incubated with HPA $(25 \mu \mathrm{g} / \mathrm{ml})$. Bar $=25 \mu \mathrm{m}$.

The presence of the capsule does not appear to hinder HPA binding to the S. pneumoniae surface since strains D39 (serotype 2) and P007 (a heavily encapsulated serotype 3 transformant) were efficiently labeled (Figures 2B,C). Cells of S. pneumoniae D39 were also positive for HPA binding when diluted to $2.5 \times 10^{6} \mathrm{cfu} / \mathrm{ml}$ into defibrinated sheep blood or into fetal bovine serum, although excess fluorescence on the erythrocyte surface may partly hinder a distinct pneumococcal identification (Figure 4). As HPA also binds to the human blood group A antigen (Matsui et al., 2001), that interference, which is due to the fact that sheep erythrocytes harbor FA on their surface (see above), should disappear using group non-A 


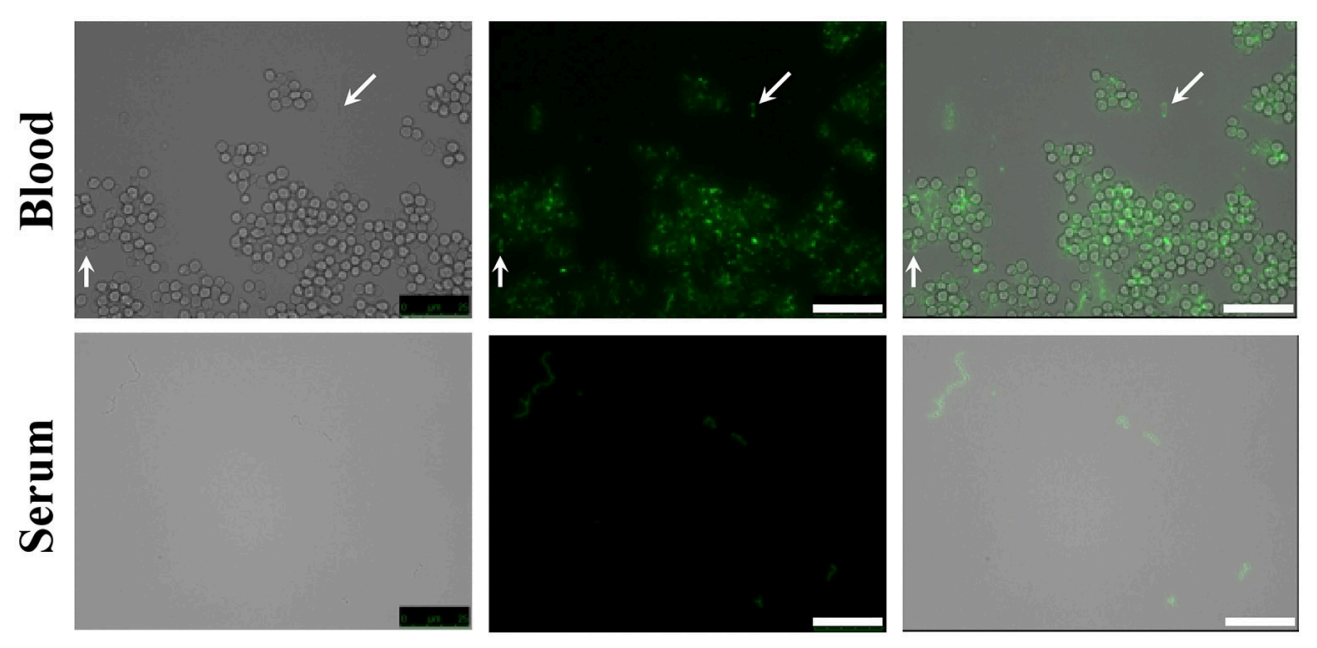

FIGURE 4 | HPA labeling of S. pneumoniae in non-human blood and serum. The type 2 encapsulated S. pneumoniae strain D39 was diluted to $2.5 \times 10^{6}$ cfu/ml into sheep blood or fetal bovine serum (63× objective). Cultures were incubated with HPA $(25 \mu \mathrm{g} / \mathrm{ml})$. Arrows point to pneumococcal cells. Bar $=25 \mu \mathrm{m}$.

(e.g., group O) human whole blood. In addition, it should be mentioned that up to 98 pneumococcal capsular polysaccharides differing in sugar composition and linkages have been described to date (Geno et al., 2017). Besides, invasive pneumococcal disease and pneumonia rates have decreased in most countries following the introduction of conjugate pneumococcal vaccines (PCVs). However, after PCV implementation, current data show that more non-vaccine serotypes increased in frequency than decreased, which is consistent with vaccine-induced replacement. Clinical pneumococcal isolates of six different serotypes-including three emerging serotypes that are currently among the predominant non-PCV13 serotypes worldwide, i.e., serotypes 12F, 22F, and 23B; Balsells et al., 2017)-were diluted to about $2.5 \times 10^{6} \mathrm{cfu} / \mathrm{ml}$ into whole human blood, incubated with HPA, and observed under the microscope. Moreover, due to the increasing clinical importance of nonencapsulated S. pneumoniae (Keller et al., 2016), a representative strain (MNZ67) was also investigated. All the pneumococcal isolates tested bound the lectin and, as expected, HPA-labeled pneumococci were particularly noticeable using group $\mathrm{O}$ human blood (Figure 5). It is worth mentioning that any possible interference caused by an excess fluorescence on the surface of group A human erythrocytes could be virtually abolished by partly sedimenting the blood cells at low speed $(1,000 \times \mathrm{g} ; 1 \mathrm{~min}$; room temperature) before HPA addition (Figure 5A, bottom right).

\section{HPA Labeling of Pneumococcal Teichoic Acids}

With the possible exception of S. pseudopneumoniae (González et al., 2008), the nutritional requirement of pneumococci for the amino alcohol choline (as a component of pnWTA and pnLTA) appears to be an exclusive trait (Rane and Subbarow, 1940). Nevertheless, several choline-independent pneumococcal mutants have been characterized in the last years, and it has been suggested that the absence of choline incorporation might affect the structure of TAs as well as the composition of the cell wall. Actually, it has been shown that pnLTA and pnWTA isolated from these mutants were free of phosphocholine and other phosphorylated aminoalcohols (Yother et al., 1998). However, and as deduced from the in vivo cell labeling with HPA of two double $t a c F$ mutants that form long chains of cells (and are autolysis-defective) when grown in media lacking any amino alcohol (strains JY2190 and P501), the absence of choline residues in TAs does not appear to modify HPA binding by S. pneumoniae (Figure 6).

It is well known that pneumococci growing in Cden medium containing EA instead of choline form long chains, do not autolyze, and are non-transformable (Tomasz, 1968). In the present work, the EA-grown cells were unable to bind HPA (Figures 7A,D). The same was seen when S. pneumoniae R6 was incubated in $\mathrm{C}+\mathrm{Y}$ supplemented with $2 \%$ choline chloride (data not shown). It has been reported that upon the addition of choline $(5 \mu \mathrm{g} / \mathrm{ml})$ to EA-grown pneumococci, these cells revert to the normal phenotype (Tomasz et al., 1975). As expected, EA-grown cells became entirely HPAlabeled $180 \mathrm{~min}(\approx 4$ generations) after shifting to a cholinecontaining medium (Figures $7 \mathbf{B}, \mathbf{E}$ ). As an alternative and complementary model, we examined the S. mitis strain SK598, which is unique in that its WTA and LTA contain EA instead of choline even when incubated in a choline-containing medium (Bergström et al., 2003). As observed for EA-grown S. pneumoniae cells, S. mitis SK598 was unable to bind HPA (Figures 7C,F).

\section{DISCUSSION}

In a previous work we have shown that, in contrast to $S$. pneumoniae, NT $H$. influenzae strains did not bind HPA; thus fluorescent staining of $S$. pneumoniae with the HPA lectin revealed that pneumococci were evenly distributed throughout the in vitro biofilm and interspersed with NT $H$. influenzae 
A
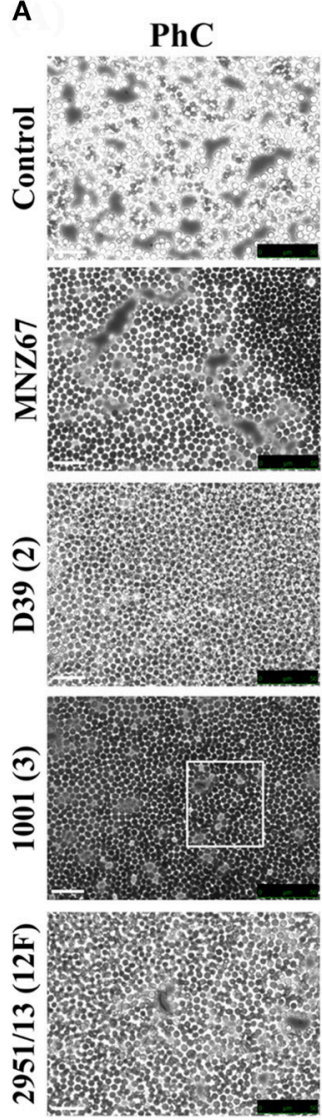

Fluorescence
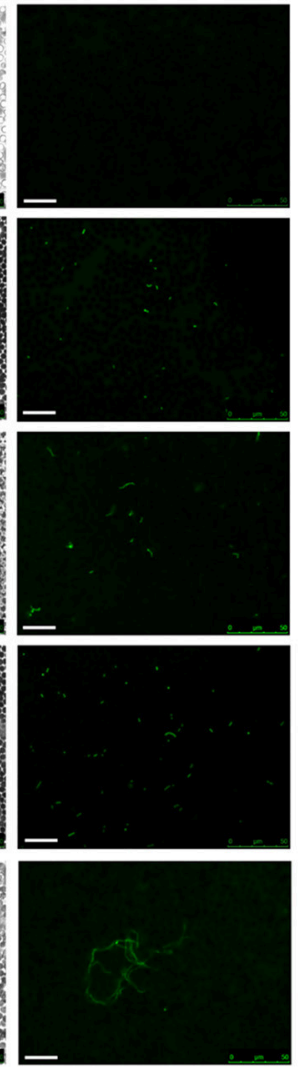
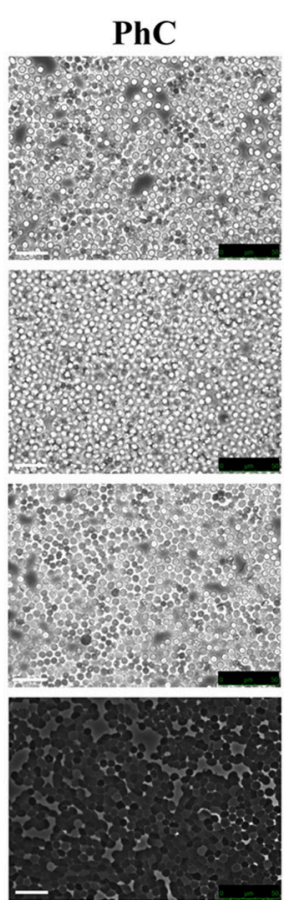

PhC
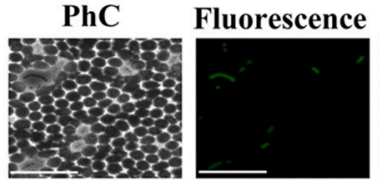

Fluorescence

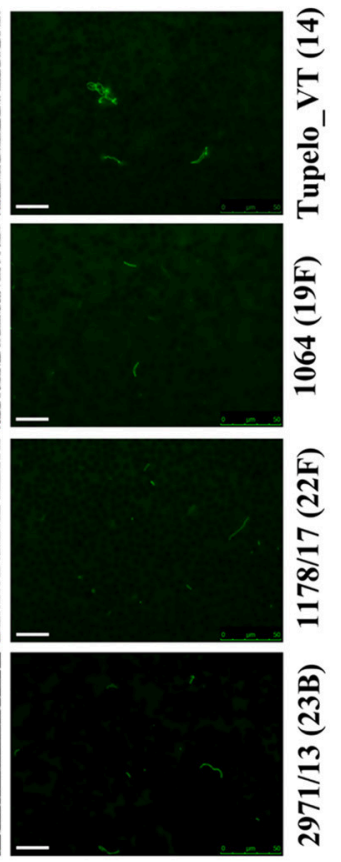

$1001(3)^{*}$

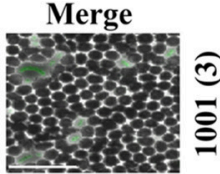

$1001(3)$
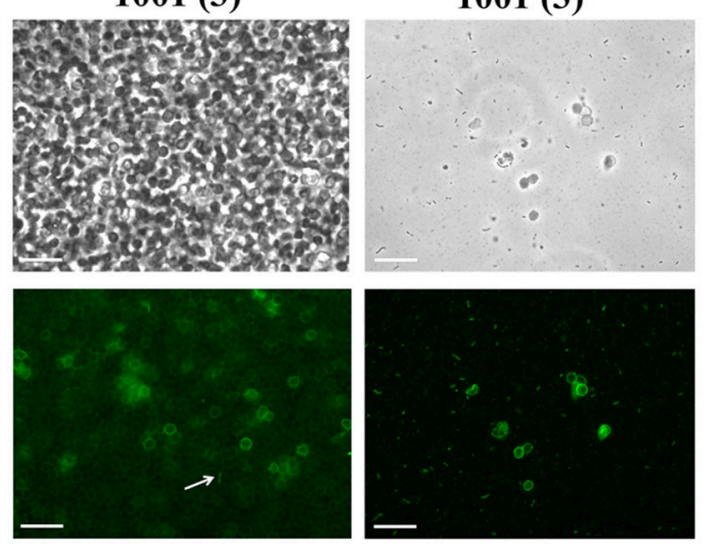

FIGURE 5 | HPA labeling of clinical pneumococcal isolates in human blood. The S. pneumoniae strains were diluted to $2.5 \times 10^{6} \mathrm{cfu} / \mathrm{ml}$ into group O (A) and A (B) human blood (40x objective). Serotypes are indicated in parentheses. Strain MNZ67 is a non-encapsulated clinical isolate. In (A), the images shown at the bottom right are enlarged visions of the area marked with a rectangle in strain 1001. Control denotes non-infected blood samples. In (B), those labeled with an asterisk correspond to views of the supernatant of infected group A blood that had been centrifuged (1,000 $\times \mathrm{g} ; 1 \mathrm{~min}$; room temperature) before HPA labeling. Samples were incubated with HPA $(25 \mu \mathrm{g} / \mathrm{ml})$. The arrow points to a pneumococcal diplococcus. Phc, phase-contrast micrograph; Bar $=25 \mu \mathrm{m}$.

(Domenech and García, 2017). We have shown here that HPA recognition of the $S$. pneumoniae surface does not require the presence of choline residues in TAs. This observation is in agreement with the results of Gisch et al. who recently reported that the presence/absence of phosphorylcholine in the
FA terminus of pnLTA to have no effect on detection by an antiForssman antibody (Gisch et al., 2013). This is relevant since the number of repeating units and the phosphocholine content per repeat (mono-substituted or di-substituted) for pneumococcal TAs slightly vary among strains (Gisch et al., 2015a). It is 
interesting, however, that, in the present work, EA-grown cells or S. pneumoniae R6 incubated in $\mathrm{C}+\mathrm{Y}$ supplemented with $2 \%$ choline chloride did not bind HPA. Incubation in high choline concentrations inhibits cell separation, leaving pneumococci to grow in long chains of cells, just like EA-grown cells (Briese and Hakenbeck, 1984; Giudicelli and Tomasz, 1984). This phenotype is, at least partly, the result of the inhibition of LytB-a member of the family of choline-binding proteins (CBPs) - and the release of this and other CBPs to the medium (López and García, 2004). Both processes would be expected to occur in cholineindependent strains growing in the absence of any amino alcohol (see above), although when this was performed in the present work HPA-labeling was unaffected. Interestingly, in an early study, Briles and Tomasz reported the yield of heterophile (sheep hemolytic) antibodies elicited by pneumococci to be at least 10-fold greater in choline- than in EA-containing media (Briles and Tomasz, 1975). Moreover, these authors reported that pneumococci growing in $\mathrm{C}+\mathrm{Y}$ medium (choline-containing) elicit antibodies which bind poorly to EA-grown bacteria, whereas the latter elicit antibodies which bind well to cholinegrown cells. The reasons for these unexpected results are still unclear, although the possibility of the existence of a cholinedependent regulatory pathway for the synthesis of pneumococcal TAs warrants future research.

To our knowledge, the concentration of free choline (or EA) in human lungs has not been reported so far. However, the normal levels of free choline and EA in human fluids are quite similar, e.g., about $1 \mu \mathrm{M}$ each in serum (Forteschi et al., 2016; Dereziński et al., 2017) and $2 \mu \mathrm{M}$ for choline or $9-15 \mu \mathrm{M}$ for EA in cerebrospinal fluid (CSF) (Kruse et al., 1985; Frölich et al., 1998; Ogawa et al., 2015). These data together with the early findings that choline is an effective inhibitor of the cellular incorporation of EA: addition of as little as $0.1 \mu \mathrm{g} / \mathrm{ml}$ choline to a culture growing in the presence of $40 \mu \mathrm{g} / \mathrm{ml} \mathrm{EA}$ immediately inhibited further EA incorporation, and that choline was incorporated by such cultures without any detectable lag (Tomasz, 1968), strongly suggest that EA-grown cells (or pneumococci grown in high choline concentrations) are not expected to be found in nature, although they represent important model systems for in vitro studies.

HPA labeling allows the recognition of S. pneumoniae cells among a variety of other species. However, it is clear that HPA specificity is not restricted to pneumococci (Table 1). Interestingly, neither $S$. pseudopneumoniae ${ }^{\mathrm{T}}, S$. mitis $^{\mathrm{T}}$ nor $S$. oralis $^{\mathrm{T}}$ binds the lectin; this is of note since, although these three species are very closely related to $S$. pneumoniae, monoclonal antibodies directed against the backbone and the phosphocholine residues of TAs react only with some strains of these three species (Kilian et al., 2008). The binding of HPA to these bacteria could, therefore, be mostly strainspecific. For example, in contrast to that observed for $S$. mitis $^{\mathrm{T}}$, S. mitis SK137 was susceptible to HPA labeling (Table 1). This was not unexpected since this particular strain has cholinecontaining TAs with a carbohydrate backbone identical to that of pnWTA/pnLTA, which forms the Lancefield group O antigen (Bergström et al., 2000). Quite unexpectedly, the SK137 strain only showed an average $67.1 \%$ nucleotide similarity to the

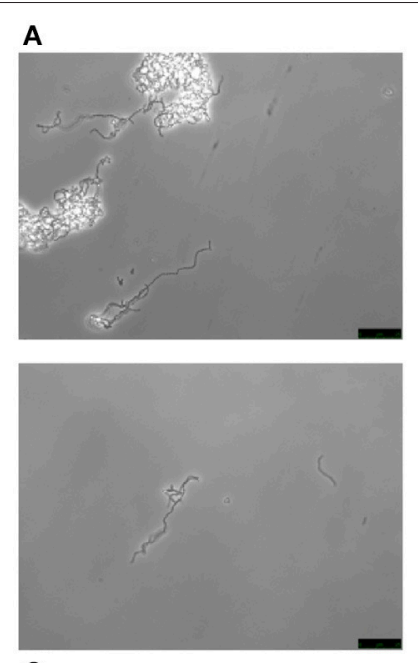

C

FIGURE 6 | HPA labeling of two choline-independent S. pneumoniae strains. Pneumococcal strains JY2190 (A,B) and P501 (C,D) were incubated in a chemically-defined medium (Cden) lacking any amino alcohol, and labeled with HPA $(25 \mu \mathrm{g} / \mathrm{ml})$. Bar $=25 \mu \mathrm{m}$.

S. mitis $^{\mathrm{T}}$ in a DNA-DNA hybridization assay (Kilian et al., 2008), slightly below the $70 \%$ level typically expected for two strains of the same species (Wayne et al., 1987). Whether strain SK137 represents a distinct species is, however, debatable, according to recent taxonomic proposals (Tindall et al., 2010).

The type strain of S. oralis (NCTC 11427) - the LTA structure of which is unknown-did not bind HPA (Table 1). However, a recent study has revealed that, in contrast to pnLTA, in which the structural element $\alpha$ GalNAc $1 \rightarrow 3 \beta$ GalNAc $1 \rightarrow$ is present (Gisch et al., 2013), only a $\beta$ GalNAcl $\rightarrow$ moiety is detectable in the $S$. oralis Uo5 LTA repeating unit (Gisch et al., 2015b). Assuming an identical LTA structure for S. oralis ${ }^{\mathrm{T}}$, the lack of the $\alpha \mathrm{GalNAcl} \rightarrow$ residue at the non-reducing end would fit in with the absence of HPA labeling. It should be underlined that at least three biochemical variants of choline-containing TAs may occur in $S$. oralis and some $S$. mitis strains, according to recent results (Denapaite et al., 2016).

Among the few other bacterial species tested, Lancefield group $\mathrm{C}$ and D streptococci were positive for HPA labeling. These results were expected in view of previous reports of Streptococcus belonging to groups C (Coligan et al., 1977; Sørensen and Henrichsen, 1987; Köhler and Nagai, 1989) and D (Kurl et al., 1989). From a diagnostic perspective, however, it is important to underline that non-pneumococcal, viridans (i.e., $\alpha$-hemolytic) streptococci are usually considered as commensals and seldom cause CAP. It is well known that viridans streptococci produce a range of invasive disease in humans (e.g., infective endocarditis) and are also emerging as a cause of bloodstream infections, but mainly in immunocompromised patients (Doern and Burnham, 2010). S. dysgalactiae subsp. equisimilis, which belongs to the $\beta$ hemolytic group $\mathrm{C}$ and $\mathrm{G}$ pyogenic group of streptococci, also binds HPA and is also currently considered as an emergent 
A
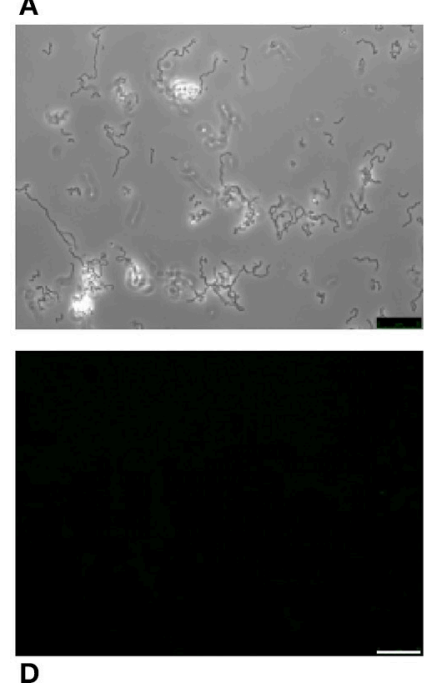

B
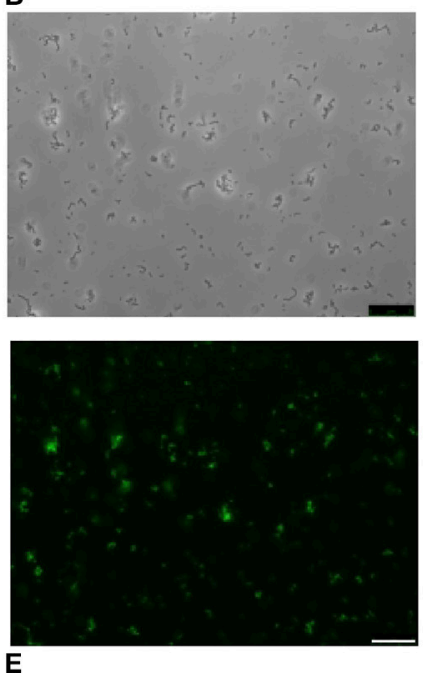

c
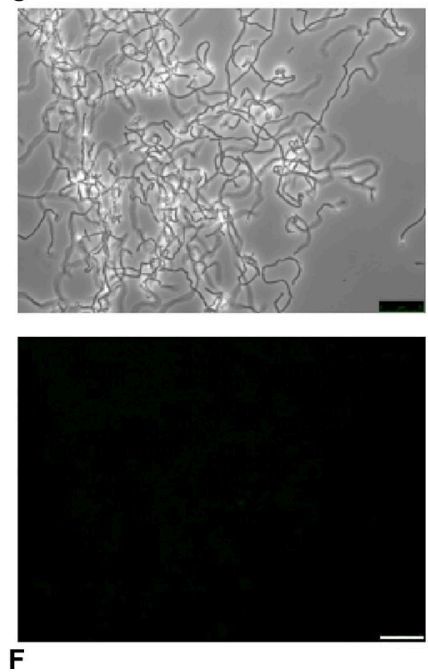

FIGURE 7 | Lack of HPA labeling in ethanolamine-containing streptococci. S. pneumoniae R6 cells were incubated for several generations in Cden medium containing ethanolamine (Cden-EA) (A,D). A portion of the culture then received choline chloride $(5 \mu \mathrm{g} / \mathrm{ml})$ and incubation proceeded at $37^{\circ} \mathrm{C}$ for $3 \mathrm{~h}$ (B,E). The S. mitis SK598 strain was grown in THY medium (C,F). The three cultures were incubated with HPA (25 $\mu \mathrm{g} / \mathrm{ml})$ (D-F). Bar $=25 \mu \mathrm{m}$.

human pathogen. Nevertheless, and as mentioned above for viridans streptococci, it is a frequent cause of invasive disease only in patients having underlying conditions (Broyles et al., 2009).

S. aureus is an important opportunistic pathogen that persistently colonizes about $20 \%$ of the human population and is intermittently associated with the remainder. This organism is one of the most frequent and important human pathogens and is implicated in a range of infections, including superficial skin infections, abscesses, and food poisoning as well as life-threatening invasive diseases (Tong et al., 2015). Although, S. aureus possesses surface carbohydrates that might be recognized by HPA (Krivan et al., 1988; Payne et al., 1992), the molecular basis for HPA binding is not well understood. It has been shown, however, that certain methicillin-susceptible S. aureus isolates-in particular those belonging to the atypical sequence type (ST) 395 lineage (e.g., strain PS187; Winstel et al., 2013) - produce a glycerol TA modified with $\alpha$ GalNAc (Winstel et al., 2014; Lee et al., 2015) that may be responsible for HPA binding. It should be noted, however, that the chemical structures of WTA and LTA of $S$. aureus are similar but not identical (Xia et al., 2010; Brown et al., 2013), that the ST of the type strain of S. aureus (ST8) is only distantly related to ST395, and that strain PS187 appears to be more closely related to several coagulasenegative staphylococcal species than to other $S$ aureus isolates (Winstel et al., 2013); the ST of S. aureus 15981 is unknown. It has been demonstrated that staphylococci can be accurately differentiated from streptococci in Gram-stained preparations (cocci in clusters and diplococci or short chains, respectively; Agger and Maki, 1978), and that S. aureus is more uncommon than the latter in CAP and acute meningitis cases. However, our results warrant additional studies to determine whether HPA labeling is common among S. aureus isolates, particularly in methicillin-resistant isolates that represent a global health care problem (Tong et al., 2015).

In agreement with a previous report (Domenech and García, 2017), NT H. influenzae strains did not bind HPA; identical results are shown here for $P$. aeruginosa PAO1. Together with $S$. pneumoniae, both Gram-negative species are common in biofilms formed during acute otitis media and live-threatening, chronic respiratory diseases such as chronic obstructive pulmonary disease or cystic fibrosis (Blasi et al., 2016). The use of HPA as S. pneumoniae-specific lectin for fluorescence imaging should provide a powerful tool for future research on these and other relevant human pathogens forming multispecies biofilms.

HPA labeling combined with Gram staining and/or antigen detection may also constitute an appropriate combination for the rapid diagnosis of CAP and, perhaps, other conditions such as bacterial meningitis (McGill et al., 2016). This may facilitate the rapid implementation of an appropriate antibiotic regime, which is conditional on the age of the patient and the regional rate of decreased susceptibility of $S$. pneumoniae to $\beta$-lactam antibiotics (van de Beek et al., 2016). As a proof of concept, cultures of pneumococci, $H$. influenzae and GBS were mixed either with sheep blood or fetal bovine serum. Also using human whole blood, only pneumococci (either encapsulated or nonencapsulated) were clearly identified by HPA labeling when used at a relatively low bacterial concentration $\left(2.5 \times 10^{6} \mathrm{cfu} / \mathrm{ml}\right)$. This concentration is lower than that frequently found in the blood of CAP patients (between $7 \times 10^{7}$ and $8 \times 10^{8} \mathrm{cfu} / \mathrm{ml}$; Gadsby et al., 2016) or in the CSF of children with confirmed pneumococcal meningitis (median bacterial load $\approx 5 \times 10^{7}$ DNA copies $/ \mathrm{ml}$ ) at the time of admittance (Roine et al., 2009). If required, 
bacteria could be concentrated by centrifugation before or after staining.

There are a number of limitations to our study: (1) although the HPA labeling technique does not require a very specialized personnel, fluorescence microscopy may be unavailable in many laboratories of developing countries. To circumvent this problem, biotinilated HPA, and alkaline phosphatase- or ferritin-conjugated HPA could be employed. (2) Only seven different bacterial genera-including 15 streptococcal and 3 staphylococcal strains-, were tested. It should be noted, however, that the bacteria tested here include some of the microorganisms most frequently causing CAP and other severe diseases. (3) Although pneumococci and staphylococci are morphologically different, the finding that two S. aureus strains also bind HPA may sometimes represent a diagnostic drawback and deserves further research. It should be noted, however, that, for example, severe sepsis-a serious complication of CAPis caused by $S$. pneumoniae about 100 times more frequently than by $S$. aureus, whereas methicillin-resistant $S$. aureus is an important cause of antimicrobial-resistant hospital-acquired infections worldwide and remains a public health priority in Europe (Montull et al., 2016). (4) This represents an in vitro study

\section{REFERENCES}

Agger, W. A., and Maki, D. G. (1978). Efficacy of direct Gram stain in differentiating staphylococci from streptococci in blood cultures positive for gram-positive cocci. J. Clin. Microbiol. 7, 111-113.

Ahmed, S., Shapiro, N. L., and Bhattacharyya, N. (2014). Incremental health care utilization and costs for acute otitis media in children. Laryngoscope 124, 301-305. doi: 10.1002/lary.24190

Amann, R., and Fuchs, B. M. (2008). Single-cell identification in microbial communities by improved fluorescence in situ hybridization techniques. Nat. Rev. Micro. 6, 339-348. doi: 10.1038/ nrmicro1888

Balsells, E., Guillot, L., Nair, H., and Kyaw, M. H. (2017). Serotype distribution of Streptococcus pneumoniae causing invasive disease in children in the postPCV era: a systematic review and meta-analysis. PLOS ONE 12:e0177113. doi: 10.1371 /journal.pone.0177113

Bergström, N., Jansson, P. -E., Kilian, M., and Sørensen, U. B. S. (2003). A unique variant of streptococcal group O-antigen (Cpolysaccharide) that lacks phosphocholine. Eur. J. Biochem. 270, 2157-2162. doi: 10.1046/j.1432-1033.2003.03569.x

Bergström, N., Jansson, P. E., Kilian, M., and Sørensen, U. B. S. (2000). Structures of two cell wall-associated polysaccharides of a Streptococcus mitis biovar 1 strain. A unique teichoic acid-like polysaccharide and the group $\mathrm{O}$ antigen which is a C-polysaccharide in common with pneumococci. Eur. J. Biochem. 267, 7147-7157. doi: 10.1046/j.1432-1327.2000.01821.x-i2

Blasi, F., Page, C., Rossolini, G. M., Pallecchi, L., Matera, M. G., Rogliani, P., et al. (2016). The effect of $\mathrm{N}$-acetylcysteine on biofilms: implications for the treatment of respiratory tract infections. Respir. Med. 117, 190-197. doi: 10.1016/j.rmed.2016.06.015

Briese, T., and Hakenbeck, R. (1984). "Influence of lipoteichoic acid and choline on the autolytic enzyme activity of Streptococcus pneumoniae," in Microbial Cell Wall Synthesis and Autolysis, ed C. Nombela (Amsterdam: Elsevier Science Publishers), 201-206.

Briles, E. B., and Tomasz, A. (1973). Pneumococcal Forssman antigen. A cholinecontaining LTA. J. Biol. Chem. 248, 6394-6397.

Briles, E. B., and Tomasz, A. (1975). Physiological studies on the pneumococcal Forssman antigen: a choline-containing lipoteichoic acid. J. Gen. Microbiol. 86, 267-274. doi: 10.1099/00221287-86-2-267 and an appropriate evaluation of the benefits of HPA labeling for diagnostic purposes should be performed directly with clinical samples, e.g., sputum, brochoalveolar fluid, blood, and/or CSF.

\section{AUTHOR CONTRIBUTIONS}

$\mathrm{MD}$ and $\mathrm{EG}$ conceived and designed the experiments. MD performed the experiments. MD and EG analyzed the data and wrote the paper.

\section{ACKNOWLEDGMENTS}

The authors thank M. H. Nam (University of Alabama at Birmingham, USA) for kindly providing strain MNZ67, M. Moscoso, J. Yuste, and P. García for helpful comments and for critically reading the manuscript, A. Burton for correcting the English version, and E. Cano and S. Ruiz for skillful technical assistance. This work was supported by a grant from the Ministerio de Economía y Competitividad (MINECO) (SAF2012-39444-C02-01). CIBER de Enfermedades Respiratorias (CIBERES) is an initiative of the Instituto de Salud Carlos III.

Brown, S., Santa Maria, J. P. Jr., and Walker, S. (2013). Wall teichoic acids of gram-positive bacteria. Annu. Rev. Microbiol. 67, 313-336. doi: 10.1146/annurev-micro-092412-155620

Broyles, L. N., Van Beneden, C., Beall, B., Facklam, R., Shewmaker, P. L., Malpiedi, P., et al. (2009). Population-based study of invasive disease due to $\beta$-hemolytic streptococci of groups other than A and B. Clin. Infect. Dis. 48, 706-712. doi: $10.1086 / 597035$

Chochua, S., D’Acremont, V., Hanke, C., Alfa, D., Shak, J., Kilowoko, M., et al. (2016). Increased nasopharyngeal density and concurrent carriage of Streptococcus pneumoniae, Haemophilus influenzae, and Moraxella catarrhalis are associated with pneumonia in febrile children. PLoS ONE 11:e0167725. doi: 10.1371/journal.pone.0167725

Cilloniz, C., Martin-Loeches, I., Garcia-Vidal, C., San Jose, A., and Torres, A. (2016). Microbial etiology of pneumonia: epidemiology, diagnosis and resistance patterns. Int. J. Mol. Sci. 17:2120. doi: 10.3390/ijms17122120

Clark, J. E. (2015). Determining the microbiological cause of a chest infection. Arch. Dis. Child. 100, 193-197. doi: 10.1136/archdischild-2013-305742

Coligan, J. E., Fraser, B. A., and Kindt, T. J. (1977). A disaccharide hapten from streptococcal group $\mathrm{C}$ carbohydrate that cross-reacts with the Forssman glycolipid. J. Immunol. 118, 6-11.

Cooling, L. (2015). Blood groups in infection and host susceptibility. Clin. Microbiol. Rev. 28, 801-870. doi: 10.1128/CMR.00109-14

Dekker, J. P., and Lau, A. F. (2016). An update on the Streptococcus bovis group: classification, identification, and disease associations. J. Clin. Microbiol. 54, 1694-1699. doi: 10.1128/JCM.02977-15

Denapaite, D., Rieger, M., Köndgen, S., Brückner, R., Ochigava, I., Kappeler, P., et al. (2016). Highly variable Streptococcus oralis strains are common among viridans streptococci isolated from primates. mSphere 1:e00041-15. doi: 10.1128/mSphere.00041-15

Dereziński, P., Klupczynska, A., Sawicki, W., Pałka, J. A., and Kokot, Z. J. (2017). Amino acid profiles of serum and urine in search for prostate cancer biomarkers: a pilot study. Int. J. Med. Sci. 14, 1-12. doi: 10.7150/ijms. 15783

Doern, C. D., and Burnham, C.-A. D. (2010). It's not easy being green: the viridans group streptococci, with a focus on pediatric clinical manifestations. J. Clin. Microbiol. 48, 3829-3835. doi: 10.1128/JCM.01563-10

Domenech, M., and García, E. (2017). N-Acetyl-L-cysteine and cysteamine: new strategies against mixed biofilms of non-encapsulated Streptococcus 
pneumoniae and non-typeable Haemophilus influenzae. Antimicrob. Agents Chemother. 61:e01992-16. doi: 10.1128/AAC.01992-16

Domenech, M., Damián, D., Ardanuy, C., Liñares, J., Fenoll, A., and García, E. (2015). Emerging, non-PCV13 serotypes 11A and 35B of Streptococcus pneumoniae show high potential for biofilm formation in vitro. PLoS ONE 10:e0125636. doi: 10.1371/journal.pone.0125636

Domenech, M., García, E., and Moscoso, M. (2009). Versatility of the capsular genes during biofilm formation by Streptococcus pneumoniae. Environ. Microbiol. 11, 2542-2555. doi: 10.1111/j.1462-2920.2009.01979.x

Domenech, M., García, E., and Moscoso, M. (2011). In vitro destruction of Streptococcus pneumoniae biofilms with bacterial and phage peptidoglycan hydrolases. Antimicrob. Agents Chemother. 55, 4144-4148. doi: 10.1128/AAC.00492-11

Ewig, S., Birkner, N., Strauss, R., Schaefer, E., Pauletzki, J., Bischoff, H., et al. (2009). New perspectives on community-acquired pneumonia in 388406 patients. Results from a nationwide mandatory performance measurement programme in healthcare quality. Thorax 64, 1062-1069. doi: 10.1136/thx.2008.109785

Forteschi, M., Zinellu, A., Assaretti, S., Mangoni, A. A., Pintus, G., Carru, C., et al. (2016). An isotope dilution capillary electrophoresis/tandem mass spectrometry (CE-MS/MS) method for the simultaneous measurement of choline, betaine, and dimethylglycine concentrations in human plasma. Anal. Bioanal. Chem. 408, 7505-7512. doi: 10.1007/s00216-016-9848-6

Frölich, L., Dirr, A., Götz, M. E., Gsell, W., Reichmann, H., Riederer, P., et al. (1998). Acetylcholine in human CSF: methodological considerations and levels in dementia of Alzheimer type. J. Neural Transm. 105, 961-973. doi: 10.1007/s007020050105

Gadsby, N. J., Russell, C. D., McHugh, M. P., Mark, H., Conway Morris, A., Laurenson, I. F., et al. (2016). Comprehensive molecular testing for respiratory pathogens in community-acquired pneumonia. Clin. Infect. Dis. 62, 817-823. doi: $10.1093 / \mathrm{cid} / \operatorname{civ} 1214$

García-Cobos, S., Moscoso, M., Pumarola, F., Arroyo, M., Lara, N., Pérez-Vázquez, M., et al. (2014). Frequent carriage of resistance mechanisms to $\beta$-lactams and biofilm formation in Haemophilus influenzae causing treatment failure and recurrent otitis media in young children. J. Antimicrob. Chemother. 69, 2394-2399. doi: 10.1093/jac/dku158

Geno, K. A., Saad, J. S., and Nahm, M. H. (2017). Discovery of novel pneumococcal serotype 35D, a natural WciG-deficient variant of serotype 35B. J. Clin. Microbiol. 55, 1416-1425. doi: 10.1128/JCM.00054-17

Gisch, N., Kohler, T., Ulmer, A. J., Müthing, J., Pribyl, T., Fischer, K., et al. (2013). Structural reevaluation of Streptococcus pneumoniae lipoteichoic acid and new insights into its immunostimulatory potency. J. Biol. Chem. 288, 15654-15667. doi: 10.1074/jbc.M112.446963

Gisch, N., Peters, K., Zähringer, U., and Vollmer, W. (2015a). "The pneumococcal cell wall," in Streptococcus pneumoniae: Molecular Mechanisms of HostPathogen Interactions, eds J. Brown, S. Hammerschimdt, and C. Orihuela (San Diego, CA: Elsevier, Inc.), 145-167.

Gisch, N., Schwudke, D., Thomsen, S., Heb, N., Hakenbeck, R., and Denapaite, D. (2015b). Lipoteichoic acid of Streptococcus oralis Uo5: a novel biochemical structure comprising an unusual phosphorylcholine substitution pattern compared to Streptococcus pneumoniae. Sci. Rep. 5:16718. doi: $10.1038 /$ srep 16718

Giudicelli, S., and Tomasz, A. (1984). "Inhibition of the in vitro and in vivo activity of the pneumococcal autolytic enzyme by choline and phosphorylcholine," in Microbial Cell Wall Synthesis and Autolysis, ed C. Nombela (Amsterdam: Elsevier Science Publishers), 207-212.

González, A., Llull, D., Morales, M., García, P., and García, E. (2008). Mutations in the $t a c F$ gene of clinical strains and laboratory transformants of Streptococcus pneumoniae: impact on choline auxotrophy and growth rate. J. Bacteriol. 190, 4129-4138. doi: 10.1128/JB.01991-07

Hajjeh, R., Mulholland, K., Schuchat, A., and Santosham, M. (2013). Progress towards demonstrating the impact of Haemophilus influenzae type b conjugate vaccines globally. J. Pediatr. 163, S1-S3. doi: 10.1016/j.jpeds.2013.03.022

Haq, I. J., Battersby, A. C., Eastham, K., and McKean, M. (2017). Community acquired pneumonia in children. BMJ 356:j686. doi: 10.1136/bmj.j686

Hoskins, J., Alborn, W. E. Jr., Arnold, J., Blaszczak, L. C., Burgett, S., DeHoff, B. S., et al. (2001). Genome of the bacterium Streptococcus pneumoniae strain R6. J. Bacteriol. 183, 5709-5717. doi: 10.1128/JB.183.19.5709-5717.2001
Jenkin, C. R. (1963). Heterophile antigens and their significance in the host-parasite relationship. Adv. Immunol. 3, 351-376. doi: 10.1016/S0065-2776(08)60816-0

Keller, L. E., Robinson, D. A., and McDaniel, L. S. (2016). Nonencapsulated Streptococcus pneumoniae: emergence and pathogenesis. mBio 7:e01792-15. doi: 10.1128/mBio.01792-15

Kilian, M., Poulsen, K., Blomqvist, T., Håvarstein, L. S., Bek-Thomsen, M., Tettelin, H., et al. (2008). Evolution of Streptococcus pneumoniae and its close commensal relatives. PLoS ONE 3:e2683. doi: 10.1371/journal.pone.0002683

Kilpper-Bälz, R., Wenzig, P., and Schleifer, K. H. (1985). Molecular relationships and classification of some viridans streptococci as Streptococcus oralis and emended description of Streptococcus oralis (Bridge and Sneath 1982). Int. J. Syst. Bacteriol. 35, 482-488. doi: 10.1099/00207713-35-4-482

Kjos, M., Aprianto, R., Fernandes, V. E., Andrew, P. W., van Strijp, J. A. G., Nijland, R., et al. (2015). Bright fluorescent Streptococcus pneumoniae for live-cell imaging of host-pathogen interactions. J. Bacteriol. 197, 807-818. doi: 10.1128/JB.02221-14

Kobayashi, Y., Tateno, H., Ogawa, H., Yamamoto, K., and Hirabayashi, J. (2014). Comprehensive list of lectins: origins, natures, and carbohydrate specificities. Methods Mol. Biol. 1200, 555-577. doi: 10.1007/978-1-4939-1292-6_45

Köhler, W., and Nagai, T. (1989). Reactions of the lectin anti-A $A_{H P}$ from the edible snail Helix pomatia with $\mathrm{N}$-acetyl-D-galactosamine of streptococci. Kitasato Arch. Exp. Med. 62, 107-113.

Krivan, H. C., Roberts, D. D., and Ginsburg, V. (1988). Many pulmonary pathogenic bacteria bind specifically to the carbohydrate sequence GalNAc $\beta 1$ 4Gal found in some glycolipids. Proc. Natl. Acad. Sci. U.S.A. 85, 6157-6161. doi: $10.1073 /$ pnas.85.16.6157

Kruse, T., Reiber, H., and Neuhoff, V. (1985). Amino acid transport across the human blood-CSF barrier. An evaluation graph for amino acid concentrations in cerebrospinal fluid. J. Neurol. Sci. 70, 129-138. doi: 10.1016/0022-510X(85)90082-6

Kurl, D. N., Haataja, S., and Finne, J. (1989). Hemagglutination activities of group B, C, D, and G streptococci: demonstration of novel sugar-specific cell-binding activities in Streptococcus suis. Infect. Immun. 57, 384-389.

Lacks, S., and Hotchkiss, R. D. (1960). A study of the genetic material determining an enzyme activity in Pneumococcus. Biochim. Biophys. Acta 39, 508-518. doi: 10.1016/0006-3002(60)90205-5

Lanie, J. A., Ng, W. -L., Kazmierczak, K. M., Andrzejewski, T. M., Davidsen, T. M., Wayne, K. J., et al. (2007). Genome sequence of Avery's virulent serotype 2 strain D39 of Streptococcus pneumoniae and comparison with that of unencapsulated laboratory strain R6. J. Bacteriol. 189, 38-51. doi: 10.1128/JB.01148-06

Lee, J. -H., Kim, N. -H., Winstel, V., Kurokawa, K., Larsen, J., An, J. -H., et al. (2015). Surface glycopolymers are crucial for in vitro anti-wall teichoic acid IgG-mediated complement activation and opsonophagocytosis of Staphylococcus aureus. Infect. Immun. 83, 4247-4255. doi: 10.1128/IAI.00767-15

Liu, W., Røder, H. L., Madsen, J. S., Bjarnsholt, T., Sørensen, S. J., and Burmølle, M. (2016). Interspecific bacterial interactions are reflected in multispecies biofilm spatial organization. Front. Microbiol. 7:1366. doi: 10.3389/fmicb.2016. 01366

López, R., and García, E. (2004). Recent trends on the molecular biology of pneumococcal capsules, lytic enzymes, and bacteriophage. FEMS Microbiol. Rev. 28, 553-580. doi: 10.1016/j.femsre.2004.05.002

Matsui, T., Hamako, J., Ozeki, Y., and Titani, K. (2001). Comparative study of blood group-recognizing lectins toward $\mathrm{ABO}$ blood group antigens on neoglycoproteins, glycoproteins and complex-type oligosaccharides. Biochim. Biophys. Acta 1525, 50-57. doi: 10.1016/S0304-4165(00)00170-7

McGill, F., Heyderman, R. S., Panagiotou, S., Tunkel, A. R., and Solomon, T. (2016). Acute bacterial meningitis in adults. Lancet 388, 3036-3047. doi: 10.1016/S0140-6736(16)30654-7

Momeni, B., Brileya, K. A., Fields, M. W., and Shou, W. (2013). Strong interpopulation cooperation leads to partner intermixing in microbial communities. eLife 2:e00230. doi: 10.7554/eLife.00230

Monasta, L., Ronfani, L., Marchetti, F., Montico, M., Vecchi Brumatti, L., Bavcar, A., et al. (2012). Burden of disease caused by otitis media: systematic review and global estimates. PLoS ONE 7:e36226. doi: 10.1371/journal.pone.0036226 
Montull, B., Menéndez, R., Torres, A., Reyes, S., Méndez, R., Zalacaín, R., et al. (2016). Predictors of severe sepsis among patients hospitalized for community-acquired pneumonia. PLoS ONE 11:e0145929. doi: 10.1371/journal.pone.0145929

Moscoso, M., Domenech, M., and García, E. (2010). Vancomycin tolerance in clinical and laboratory Streptococcus pneumoniae isolates depends on reduced enzyme activity of the major LytA autolysin or cooperation between CiaH histidine kinase and capsular polysaccharide. Mol. Microbiol. 77, 1052-1064. doi: $10.1111 / j .1365-2958.2010 .07271 . x$

Ngo, C. C., Massa, H. M., Thornton, R. B., and Cripps, A. W. (2016). Predominant bacteria detected from the middle ear fluid of children experiencing otitis media: a systematic review. PLoS ONE 11:e0150949. doi: 10.1371/journal.pone.0150949

Ogawa, S., Hattori, K., Sasayama, D., Yokota, Y., Matsumura, R., Matsuo, J., et al. (2015). Reduced cerebrospinal fluid ethanolamine concentration in major depressive disorder. Sci. Rep. 5:7796. doi: 10.1038/srep07796

Pai, S., Enoch, D. A., and Aliyu, S. H. (2015). Bacteremia in children: epidemiology, clinical diagnosis and antibiotic treatment. Expert Rev. Anti Infect. Ther. 13, 1073-1088. doi: 10.1586/14787210.2015.1063418

Park, I. H., Kim, K.-H., Andrade, A. L., Briles, D. E., McDaniel, L. S., and Nahm, M. H. (2012). Nontypeable pneumococci can be divided into multiple cps types, including one type expressing the novel gene pspK. mBio 3:e00035-12. doi: $10.1128 / \mathrm{mBio} .00035-12$

Payne, M. J., Campbell, S., Patchett, R. A., and Kroll, R. G. (1992). The use of immobilized lectins in the separation of Staphylococcus aureus, Escherichia coli, Listeria and Salmonella spp. from pure cultures and foods. J. Appl. Bacteriol. 73, 41-52. doi: 10.1111/j.1365-2672.1992.tb04967.x

Rane, L., and Subbarow, Y. (1940). Nutritional requirements of the pneumococcus. 1. Growth factors for types I, II, V, VII, VIII. J. Bacteriol. 40, 695-704.

Røder, H. L., Sørensen, S. J., and Burmølle, M. (2016). Studying bacterial multispecies biofilms: where to start? Trends Microbiol. 24, 503-513. doi: 10.1016/j.tim.2016.02.019

Roine, I., Saukkoriipi, A., Leinonen, M., Peltola, H., and LatAm Meningitis Study Group (2009). Microbial genome count in cerebrospinal fluid compared with clinical characteristics in pneumococcal and Haemophilus influenzae type b meningitis in children. Diagn. Microbiol. Infect. Dis. 63, 16-23. doi: 10.1016/j.diagmicrobio.2008.09.005

Schimak, M. P., Kleiner, M., Wetzel, S., Liebeke, M., Dubilier, N., and Fuchs, B. M. (2016). MiL-FISH: multilabeled oligonucleotides for fluorescence in situ hybridization improve visualization of bacterial cells. Appl. Environ. Microbiol. 82, 62-70. doi: 10.1128/AEM.02776-15

Seo, H. S., Cartee, R. T., Pritchard, D. G., and Nahm, M. H. (2008). A new model of pneumococcal lipoteichoic acid structure resolves biochemical, biosynthetic, and serologic inconsistencies of the current model. J. Bacteriol. 190, 2379-2387. doi: 10.1128/JB.01795-07

Shiroma, A., Terabayashi, Y., Nakano, K., Shimoji, M., Tamotsu, H., Ashimine, N., et al. (2015). First complete genome sequences of Staphylococcus aureus subsp. aureus Rosenbach 1884 (DSM 20231T), determined by PacBio single-molecule real-time technology. Genome Announc. 3:e00800-15. doi: 10.1128/genomeA.00800-15

Siddiqui, B., and Hakomori, S.-I. (1971). A revised structure for the Forssman glycolipid hapten. J. Biol. Chem. 246, 5766-5769.

Sørensen, U. B., and Henrichsen, J. (1987). Cross-reactions between pneumococci and other streptococci due to $\mathrm{C}$ polysaccharide and $\mathrm{F}$ antigen. J. Clin. Microbiol. $25,1854-1859$

Tindall, B. J., Rosselló-Móra, R., Busse, H.-J., Ludwig, W., and Kämpfer, P. (2010). Notes on the characterization of prokaryote strains for taxonomic purposes. Int. J. Syst. Evol. Microbiol. 60, 249-266. doi: 10.1099/ijs.0.016949-0

Tomasz, A. (1968). Biological consequences of the replacement of choline by ethanolamine in the cell wall of Pneumococcus: chain formation, loss of transformability, and loss of autolysis. Proc. Natl. Acad. Sci. U.S.A. 59, 86-93. doi: 10.1073/pnas.59.1.86
Tomasz, A., Westphal, M., Briles, E. B., and Fletcher, P. (1975). On the physiological functions of teichoic acids. J. Supramol. Struct. 3, 1-16. doi: $10.1002 /$ jss. 400030102

Tong, S. Y. C., Davis, J. S., Eichenberger, E., Holland, T. L., and Fowler, V. G. Jr. (2015). Staphylococcus aureus infections: epidemiology, pathophysiology, clinical manifestations, and management. Clin. Microbiol. Rev. 28, 603-661. doi: 10.1128/CMR.00134-14

Torres, A., Lee, N., Cilloniz, C., Vila, J., and Van der Eerden, M. (2016). Laboratory diagnosis of pneumonia in the molecular age. Eur. Respir. J. 48, 1764-1778. doi: 10.1183/13993003.01144-2016

Valle, J., Toledo-Arana, A., Berasain, C., Ghigo, J.-M., Amorena, B., Penadés, J. R., et al. (2003). SarA and not $\sigma^{\mathrm{B}}$ is essential for biofilm development by Staphylococcus aureus. Mol. Microbiol. 48, 1075-1087. doi: 10.1046/j.1365-2958.2003.03493.x

van de Beek, D., Cabellos, C., Dzupova, O., Esposito, S., Klein, M., Kloek, A. T., et al. (2016). ESCMID guideline: diagnosis and treatment of acute bacterial meningitis. Clin. Microbiol. Infect. 22, S37-S62. doi: 10.1016/j.cmi.2016.01.007

Vila, J., Gómez, M. D., Salavert, M., and Bosch, J. (2017). Methods of rapid diagnosis in clinical microbiology: clinical needs. Enferm. Infecc. Microbiol. Clin. 35, 41-46. doi: 10.1016/j.eimc.2016.11.004

Wayne, L. G., Brenner, D. J., Colwell, R. R., Grimont, P. A. D., Kandler, O., Krichevsky, M. I., et al. (1987). Report of the ad hoc committee on reconciliation of approaches to bacterial systematics. Int. J. Syst. Evol. Microbiol. 37, 463-464. doi: 10.1099/00207713-37-4-463

Winstel, V., Liang, C., Sanchez-Carballo, P., Steglich, M., Munar, M., Bröker, B. M., et al. (2013). Wall teichoic acid structure governs horizontal gene transfer between major bacterial pathogens. Nat. Commun. 4:2345. doi: $10.1038 /$ ncomms 3345

Winstel, V., Xia, G., and Peschel, A. (2014). Pathways and roles of wall teichoic acid glycosylation in Staphylococcus aureus. Int. J. Med. Microbiol. 304, 215-221. doi: 10.1016/j.ijmm.2013.10.009

World Health Organization (2016). Pneumonia. Geneva: World Health Organization. Available online at: http://www.who.int/mediacentre/factsheets/ fs331/en/

Wu, A. M., and Sugii, S. (1991). Coding and classification of Dgalactose, $\quad N$-acetyl-D-galactosamine, and $\quad \beta$-D-Galp-[1 $\rightarrow 3(4)]-\beta-\mathrm{D}$ GlcpNAc, specificities of applied lectins. Carbohydr. Res. 213, 127-143. doi: 10.1016/S0008-6215(00)90604-9

Xia, G., Kohler, T., and Peschel, A. (2010). The wall teichoic acid and lipoteichoic acid polymers of Staphylococcus aureus. Int. J. Med. Microbiol. 300, 148-154. doi: 10.1016/j.ijmm.2009.10.001

Yamamoto, M., Cid, E., and Yamamoto, F. (2012). Molecular genetic basis of the human Forssman glycolipid antigen negativity. Sci. Rep. 2:975. doi: $10.1038 /$ srep00975

Yother, J., Leopold, K., White, J., and Fischer, W. (1998). Generation and properties of a Streptococcus pneumoniae mutant which does not require choline or analogs for growth. J. Bacteriol. 180, 2093-2101

Conflict of Interest Statement: The other authors declare that the research was conducted in the absence of any commercial or financial relationships that could be construed as a potential conflict of interest.

The reviewer ME declared a shared affiliation, though no other collaboration, with one of the authors MD to the handling Editor, who ensured that the process nevertheless met the standards of a fair and objective review.

Copyright $\odot 2017$ Domenech and García. This is an open-access article distributed under the terms of the Creative Commons Attribution License (CC BY). The use, distribution or reproduction in other forums is permitted, provided the original author(s) or licensor are credited and that the original publication in this journal is cited, in accordance with accepted academic practice. No use, distribution or reproduction is permitted which does not comply with these terms. 